\title{
Embryonic Stem Cell-Derived Embryoid Bodies Development in Collagen Gels Recapitulates Sprouting Angiogenesis
}

\author{
Olivier Feraud, Yihai Cao, and Daniel Vittet
}

Laboratoire de Transgenèse et Différenciation Cellulaire (OF, DV), CEA Grenoble, DBMS, Grenoble, France; Laboratory of Angiogenesis Research (YC), Microbiology and Tumor Biology Center, Karolinska Institute, Stockholm, Sweden; INSERM U244 (DV), CEA Grenoble, DBMS, Grenoble, France

\begin{abstract}
SUMMARY: The formation of new blood vessels proceeds by both vasculogenesis and angiogenesis. The development of models, which fully recapitulate spatio-temporal events involved during these processes, are crucial to fully understand their mechanisms of regulation. In vitro differentiation of murine embryonic stem (ES) cells has been shown to be a useful tool to investigate factors and genes potentially involved in vasculogenesis (Hirashima et al, 1999; Risau et al, 1988; Vittet et al, 1996; Wang et al, 1992; Wartenberg et al, 1998). We asked here whether this model system can also recapitulate angiogenesis, which may offer new means to study mechanisms involved in this process. ES-derived embryoid bodies (EBs) obtained after 11 days of differentiation, in which a primitive vascular network had formed, were then subcultured into a type I collagen matrix. In the presence of angiogenic growth factors, EBs rapidly developed branching pseudopods. Whole mount immunostainings with a PECAM antibody revealed that more than $75 \%$ EBs displayed, within a few days, a large number of endothelial outgrowths that can give tube-like structures with concomitant differentiation of $\alpha$-smooth muscle actin positive cells, thus evoking sprouting angiogenesis. High expression levels of flk1 (VEGFR2), flt1 (VEGFR1), tie-1, and tie-2 are also found, indicating that budding endothelial cells displayed an angiogenic phenotype. The endothelial sprouting response was specifically induced by angiogenic factors with a major contribution of vascular endothelial growth factor (VEGF). Known angiostatic agents, such as platelet factor 4 (PF4), angiostatin, and endostatin inhibited the formation of endothelial sprouts induced by angiogenic factors. Moreover, consistent with the in vivo phenotype, VE-cadherin deficient EBs failed to develop angiogenesis in this model. ES cell differentiation can then recapitulate, in addition to vasculogenesis, the early stages of sprouting angiogenesis. This model system, in which genetic modifications can be easily introduced, may be of particular interest to investigate unsolved questions and molecular mechanisms involved in blood vessel formation. (Lab Invest 2001, 81:1669-1681).
\end{abstract}

$V$ ascularization of organs and tissues proceeds by two related but distinct processes: vasculogenesis and angiogenesis (Risau, 1997). In vasculogenesis, primitive blood vessels develop from angioblast precursor cells, which differentiate and assemble into cord-like vascular structures that further connect into a primary network. Angiogenesis corresponds to the formation of new blood vessels from the pre-existing blood vasculature by the sprouting, splitting, and remodeling of the vascular network. Angiogenesis is a complex process, which results from an ordered set of events involving endothelial cell activation, growth, migration, and capillary morphogenesis. Both vasculogenesis and angiogenesis are involved in the development of a functional vascular system in the embryo (Flamme et al, 1997), but also contribute to postnatal blood vessel formation (Asahara et al, 1997, 1999;

\section{Received July 26, 2001.}

This work was supported by grants from INSERM (contrat APEX n $99-$ 01) and from the Association pour la Recherche sur le Cancer (subvention $n^{\circ} 9586$ ).

Address reprint requests to: Dr. Daniel Vittet, Laboratoire TDC, CEA Grenoble, DBMS, 17 avenue des martyrs, 38054 Grenoble cedex 9, France.E-mail:dvittet@cea.fr
Kalka et al, 2000). In the adult, a neovascularization response occurs in a variety of physiological and pathological settings, including wound healing, recovery from myocardial infarction, inflammation-related diseases, solid tumor growth, and tumor metastasis. Numerous studies have characterized cellular and molecular factors important to vascular formation and development (Beck and D'Amore, 1997; Risau, 1997). Although intensively studied, the molecular mechanisms involved in the regulation of both vasculogenic and angiogenic responses are still not completely understood. Therefore, the development of models, which fully recapitulate spatio-temporal events involved during blood vessel formation and which exhibit a great potential for genetic investigations, appears crucial to elucidate and fully understand the regulation of these processes.

Embryonic stem (ES) cell model has been reported to be a particularly interesting tool to investigate molecular mechanisms and genes involved in mammalian development (Rathjen et al, 1998). ES cells are pluripotent cells derived from the early mouse embryo that can be propagated stably in the undifferentiated state in vitro. Since they retain the ability to differentiate into all cell types found in an embryonic and adult 
mouse in vivo, ES cells have been most extensively used to analyze gene function in development via gene targeting and homologous recombination, by generating mutant mice (Rathjen et al, 1998). ES cell lines also provide the ability to directly probe gene function during in vitro differentiation of ES cells themselves. Indeed, ES cells differentiating in vitro form embryo-like aggregates, called the embryoid bodies (EBs), and develop many cell types including hematopoietic cells, neuronal cells, cardiomyocytes and muscle cells, epithelial cells, and cells of the endothelial lineage (Rathjen et al, 1998). Several studies have indicated the occurrence of vasculogenesis in ES-derived EBs (Hirashima et al, 1999; Risau et al, 1988; Vittet et al, 1996; Wang et al, 1992; Wartenberg et al, 1998). Furthermore, we have previously established that the endothelial development within ESderived EBs, as defined by the onset of specific gene expression, follows an ordered sequence of events that recapitulates murine vasculogenesis in vivo and leads to the formation of vascular structures evoking a primitive vascular network (Vittet et al, 1996). Other experiments, performed by plating EBs onto gelatinized dishes, showed the formation of branching vascular structures indicative of extensive vascular morphogenesis from EBs (Bloch et al, 1997).

We asked here whether the ES/EB model system can further recapitulate events of the angiogenic process. Because angiogenesis involves endothelial cell migration and proliferation within a collagen-rich extracellular matrix (Strömbald and Cheresh, 1996), we investigated maturation of ES-derived EBs containing capillary-like structures into a type I collagen gel, in the absence or in the presence of angiogenic and angiostatic agents, to see whether sprouting angiogenesis can develop from the primitive vascular network seen in 11-day-old, ESderived EBs. Our findings show that 11- day-old EBs embedded into collagen gels rapidly developed, in the presence of angiogenic factors, a network of branching endothelial outgrowths that displays an angiogenic phenotype. In agreement with angiogenesis regulation mechanisms, vascular sprouting was specifically induced by known angiogenic factors and was inhibited by several angiostatic agents. Moreover, consistent with in vivo and in vitro experiments showing a vascular endothelial cadherin (VE-cadherin) role in angiogenesis and vascular remodeling, we also observed that VEcadherin-/- ES-derived EBs failed to develop endothelial sprouts within this three dimensional model. These observations indicate that the ES cell system can also be used as a model for angiogenesis and that the ES/EB model provides a unique in vitro system to gain further insights into molecular and cellular signaling mechanisms that proceed during the process of blood vessel formation.

\section{Results}

\section{Day 11-Embryoid Bodies Embedded into Collagen Form Endothelial Outgrowths}

Several studies have outlined that ES-derived EBs constitute a suitable in vitro model to study vasculo- genesis (Bloch et al, 1997; Hirashima et al, 1999; Risau et al, 1988; Vittet et al, 1996; Wang et al, 1992; Wartenberg et al, 1998). In a previous work, we showed that at least $75 \%$ of Day 11 ES-derived EBs exhibit vascular structures, evoking a primitive vascular plexus resulting from vasculogenesis, when differentiation was performed in a semi-solid methylcellulose medium in the presence of vascular growth factors (GFs) (Vittet et al, 1996). To discover whether angiogenesis may develop from this primitive network, Day 11 EBs were collected and further cultured into a type I collagen matrix under the same culture conditions, in the presence of a cocktail of angiogenic factors (VEGF, FGF2, EPO, IL6) at optimal concentrations. Type I-three dimensional collagen gel has been used because it is the major constituent of the pericapillary connective tissue in vivo, which play an important role during angiogenesis via endothelial cell surface interactions (Strömbald and Cheresh, 1996). EBs were observed to rapidly undergo shape change when subjected to 3D-culture in these conditions. Morphological observations revealed that EBs rapidly develop an extensive network of cellular outgrowths when embedded into the collagen gel (Fig. 1, A, B, and C). This cellular reorganization could occur from both EBs that have undergone previous endothelial differ-

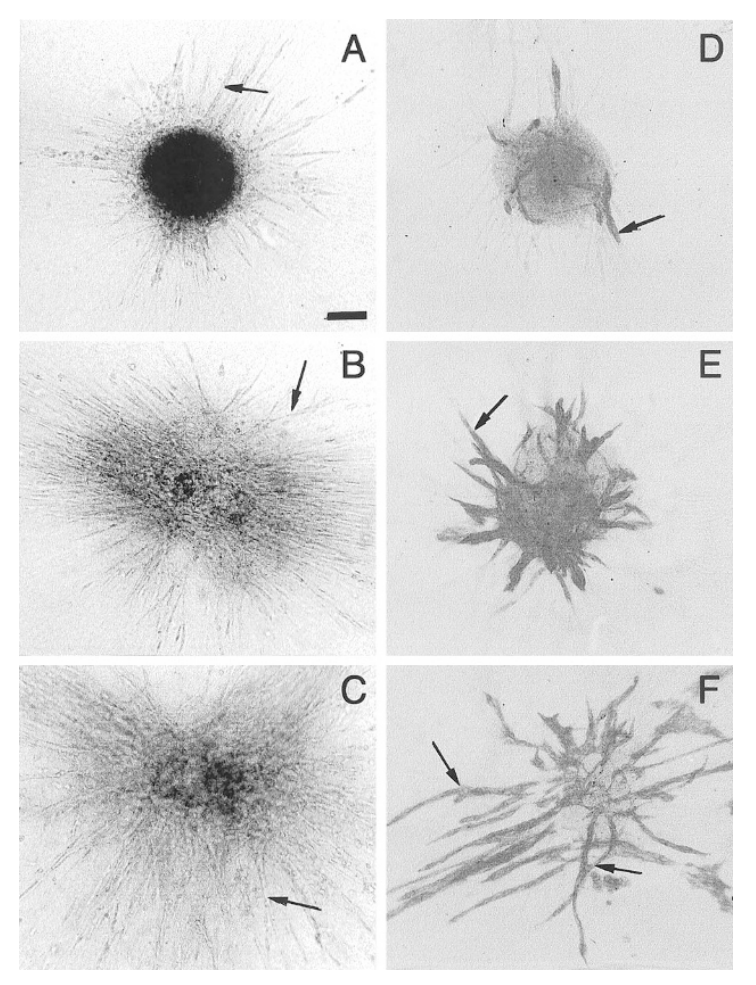

Figure 1.

Vascular morphogenesis from 11-day-old embryoid bodies (EBs) embedded into type I collagen gel in the presence of angiogenic growth factors (GFs cocktail). A, B, and C, Morphological analysis of maturation of 11-day-old EBs, 24,48 , and 72 hours after secondary culture into collagen, respectively. Arrows indicate budding outgrowths invading the collagen matrix. D, E, and F, Corresponding representative platelet endothelial cell adhesion molecule (PECAM) whole mount immunostainings of 11-day-old EBs embedded into collagen. Arrows point to expanding PECAM positive endothelial outgrowths, which further connect into a network. Scale bar: $100 \mu \mathrm{m}$ for all panels. 
entiation (classified as vascular) and from EBs devoid of endothelial cells (classified as nonvascular), as assessed by the platelet endothelial cell adhesion molecule (PECAM) immunoreactivity of the EBs that was previously demonstrated to match with endothelial cells (Vittet et al, 1996). Whole mount immunostainings with an anti-PECAM antibody bring the evidence for numerous endothelial sprouts, which emerge from the initial primitive endothelial structures within the vascular EBs, then branch, and give rise to a complex network after 48 to 72 hours of secondary culture into collagen (Fig. 1, D, E, and F). Several outgrowths are not stained by the PECAM antibody indicating that nonendothelial cells can also form sprouts in the collagen matrix, as previously described by others (Montesano et al, 1997; Uyttendaele et al, 1998). The cellular nature of these cells remains to be determined. Nevertheless, near $50 \%$ of sprouts seem to be true endothelial outgrowths and Figure 2A illustrates a characteristic branched PECAM-positive endothelial sprout end at a high magnification by differential interference contrast microscopy. It shows that the interconnected endothelial pseudopods are typically blunt-ended and are either formed by individual cells aligned end-to-end or, in many instances, constituted by the assembly of several endothelial cells.

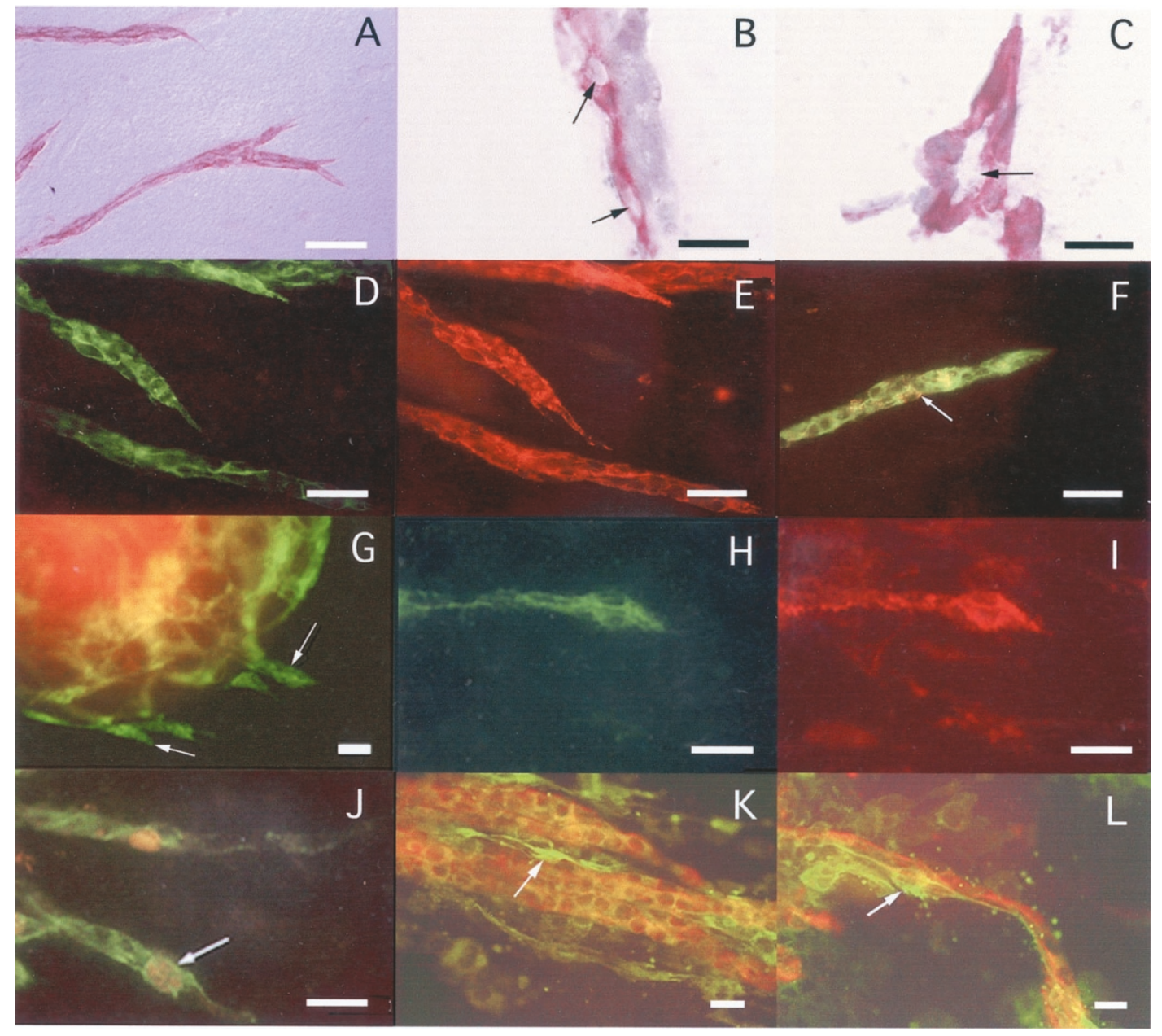

Figure 2.

Characterization of EB endothelial sprouting. A, Hoffman modulation contrast (DIC) photograph of a branching PECAM-positive endothelial sprout formed after 48 hours of secondary culture in the presence of the GF mixture, into type I collagen matrix. B and C, Hematoxylin counterstained cross-sections of PECAM-positive sprouts that reveal the formation of vacuoles (arrows in B) and tube-like structures (arrow in C). D to F, 11-day-old EBs cultured for 3 days into collagen gel and in the presence of angiogenic growth factors were processed for indirect immunofluorescence analysis with antibodies directed against endothelial antigens. Comparative distribution of PECAM (D) and vascular endothelial cadherin (VE-cadherin) (E), and of PECAM and von Willebrand factor (vWF) (F) by double labeling experiments. F, the arrow points to representative punctuated rice, grain-like staining pattern typical of vWF expression. G, Endothelial sprouts visualization by PECAM immunofluorescent staining (green) after 24 hours of secondary culture into collagen gels. White arrows indicate small PECAM positive sprouts originating from an 11-day-old EB. H, I, Detection of Flk-1 expression in endothelial outgrowths from 11-day-old EBs embedded into collagen gel. Eleven-day-old EBs cultured for 2 days into type I collagen matrix in the presence of the cocktail of angiogenic GFs were analyzed by immunofluorescent double labeling with PECAM (H) and Flk-1(I) antibodies. J, Analysis of 5-Bromo-2'-deoxyuridine (BrdU) labeling of endothelial outgrowths originating from 11-day-old EBs embedded into collagen gel. EBs cultured for 2 days into the collagen matrix in the presence of angiogenic factors were processed for BrdU labeling as described in the Materials and Methods. The presence of endothelial proliferating cells was revealed by the double labeling experiment with PECAM and BrdU antibodies. The arrow is pointed to the BrdU immunoreactivity (red staining) of the nucleus of a dividing cell positive for PECAM (green staining). K and L, Double immunostaining of endothelial sprouts after 3 days of secondary culture in the presence of angiogenic factors, for PECAM and $\alpha$-smooth muscle actin. Elongated $\alpha$-smooth muscle positive cells (green fluorescence) can be seen (arrows) close to PECAM positive cells (red fluorescence) constituting sprouts. Scale bars for all panels: $50 \mu \mathrm{m}$, with the exception of panels B, C, K and L: $25 \mu \mathrm{m}$. 
Identical vascular sprouting responses were obtained with two different ES cell lines: CJ7 (presented here) and R1 (data not shown). Cross sections of endothelial sprouts revealed the occasional formation of small vacuole-like structures (Fig. 2B), evoking the first steps of tube formation, and of larger spaces resembling lumen (Fig. 2C) that suggested the formation of capillary-like tubular structures, as described in Yang et al, 1999 and Yamashita et al, 2000, respectively. Although evidences for tube and lumen formation were infrequent at early stages of secondary culture into collagen gels, any long-term evaluation of tube formation or assessment of possible regression of tubes was prevented by degradation of the gels at times exceeding 72 hours. The endothelial phenotype of tube-like structures was examined by immunofluorescence studies. Analysis of the endothelial antigen expression revealed that vascular sprouts exhibit a complete endothelial phenotype as assessed by VEcadherin and von Willebrand factor (vWF) immunoreactivity (Fig. 2, D, E, and F).

\section{Endothelial Outgrowths Display Many Features of the Angiogenic Response}

Angiogenesis is a complex process leading to the extension of the initial vasculature by formation of vessel sprouts from pre-existing vessels. This phenomenon is characterized by the growth and the migration of endothelial cells through the surrounding matrix before their organization into vascular tubes by a morphogenetic process. In addition to the whole mount results illustrated above, immunofluorescence experiments performed after 24 hours of culture in the collagen gel indicated that endothelial sprouts originated from the initial vascular structures, which cover the surface of EBs (Fig. 2G). In addition, the development of capillary-like structures seemed to be caused by enhanced proliferation of endothelial cells. Indeed, double-labeling experiments revealed that several PECAM-positive cells constituting the sprouts had incorporated 5-Bromo-2'-deoxyuridine (BrDU) in their nuclei, which clearly indicates the presence of proliferating cells (Fig. $2 \mathrm{~J}$ ).

Angiogenesis involves an interplay between angiogenic, survival, and differentiation factors and the first steps of this process have been described to be accompanied by the rapid up-regulation or high expression levels of several endothelial receptor tyrosine kinases, which represent the major signaling system involved in the regulation of the angiogenic response (Breier et al, 1997; Gale and Yancopoulos, 1999). We assessed the distribution of one of these markers, Flk-1, by immunofluorescence. As shown in Figure 2 ( $\mathrm{H}$ and $\mathrm{I}$ ), Flk-1 immunoreactivity was found in budding PECAM-positive endothelial sprouts. By RT-PCR analysis, we also followed flk-1, flt-1, tie-1, and tie-2 gene expression pattern during EB maturation in type I collagen matrix. As expected, all transcripts were detected in 11-day-old EBs. In the absence of angiogenic factors, gene expression was down-regulated for all markers during the secondary culture in the collagen gel. In contrast, the expression level of all these angiogenic markers remained sustained or were up-regulated in budding EBs cultured in the presence of angiogenic GFs (Fig. 3). These changes were not the result of variable representation of endothelial cells in EBs, because the percentages of PECAM-positive cells were not significantly different between the two experimental conditions, as assessed by FACS analysis of the EB contents after dissociation (data not shown).

During angiogenesis, nascent blood vessels are further stabilized by the recruitment of periendothelial cells (pericytes or smooth muscle cells), essential for vascular maturation and function (Carmeliet and Collen, 2000; Sims, 2000). Immunofluorescence experiments were performed to know whether periendothelial cells can also form in this model. Elongated $\alpha$-smooth muscle actin positive cells can be found, some of them in the vicinity of endothelial cells constituting the sprouts (Fig. 2, $\mathrm{K}$ and $\mathrm{L}$ ), thus indicating the concomitant differentiation of periendothelial mural cells.

\section{Endothelial Sprouts are Specifically Induced by Angiogenic GFs}

Another question we asked was whether the observed endothelial sprouting response was stimulated by angiogenic GFs. When embedded into the collagen gel, EBs were found to develop cellular outgrowths either in the absence or in the presence of angiogenic factors. However, we found after immunostaining experiments that endothelial sprouting from vascular EBs only occurred in the presence of the exogenously added angiogenic growth factor cocktail (GFs). When
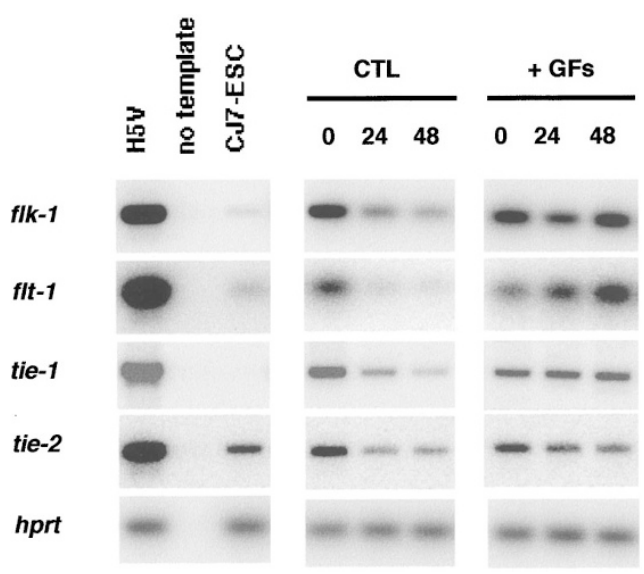

Figure 3.

RT-PCR analysis of angiogenic marker expression during 11-day-old EBs maturation into type I collagen gels. RNA was extracted from 11-day-old EBs (time 0 ) and 24 and 48 hours after secondary culture of 11-day-old EBs into type I collagen gel in the absence (CTL) or in the presence (+GFs) of angiogenic growth factor cocktail. The expression of flk-1, flt-1, tie-1, and tie-2 was examined as markers of the angiogenic phenotype. The cDNA of hprt was amplified to normalize for the amount of mRNA used as starting material. H5V, murine endothelial cell line (Garlanda et al, 1994) used as a positive control; CJ7-ESC, undifferentiated ES cells cultured in the presence of LIF; no template, negative control. Shown are data from a typical experiment out of two performed with CJ7 ES cells. 
angiogenic factors were present, $75 \% \pm 5 \%$ (SD, $n=$ 4) of EBs displayed endothelial cellular processes invading the collagen matrix after 48 hours of secondary culture (Fig. 4). The development of nonendothelial outgrowths also seemed to be enhanced by GFs, reflecting the pleiotropic actions of some of the compounds used in the cocktail, such as basic fibroblast growth factor (FGF2) (Bikfalvi et al, 1997). In contrast, EBs were unable to develop endothelial outgrowths and only nonendothelial outgrowths can form in the absence of GFs. EBs that developed endothelial outgrowths were classified as angiogenic, whereas EBs that have undergone endothelial differentiation, but have formed only nonendothelial outgrowths, were classified as nonangiogenic.

The sensitivity to vascular endothelial growth factor (VEGF) or FGF2 was then characterized more completely after quantification of the sprouting response by computerized image analysis. Both compounds were found to elicit dose-dependent stimulation of EBs' endothelial sprouting (Fig. 5). Nevertheless, the quantitative analysis of the sprouting revealed that FGF2 has only a minor contribution in the sprouting and that VEGF alone can account for around $80 \%$ of the response induced by the complete GFs cocktail (Fig. 5). Maximal responses were achieved with VEGF concentrations between 15 and $50 \mathrm{ng} / \mathrm{ml}$, which was in agreement with several previously published in vitro studies (Deckers et al, 2001; Gerber et al, 1998).

\section{Platelet Factor 4 (PF4), Angiostatin, and Endostatin Can} Inhibit Vascular Sprouting Induced by Angiogenic Factors

A number of antiangiogenic agents displaying both in vitro and in vivo biological effects have been identified.
This includes various cytokines and protein fragments of larger molecules that are not themselves inhibitors of angiogenesis in their entire form (Hanahan and Folkman, 1996). To evaluate whether agents with known antiangiogenic activity were effective in the collagen-embedded EB system, PF4, angiostatin and endostatin were tested on the sprouting response induced by angiogenic factors. Representative images obtained after treatment with maximal doses of these inhibitors are illustrated in Figure 6. They showed a defective vascular sprouting response in the presence of these inhibitors. Quantitative analysis revealed that $5 \mu \mathrm{g} / \mathrm{ml}$ PF4 significantly affected the onset of EB endothelial sprouting, because a $41 \%$ reduction in the number of EBs exhibiting endothelial outgrowths can be measured (Fig. 7). PF4 was also observed to significantly affect the total mean length of endothelial sprouts (Fig. 7). Although angiostatin and endostatin did not exert a significant reduction in the number of sprouting EBs, they markedly inhibited the density and length of endothelial sprouts in the collagen gel (Fig. 7). Treatment with 5 to $15 \mu \mathrm{g} / \mathrm{ml}$ endostatin or with 1 to $2.5 \mu \mathrm{g} / \mathrm{ml}$ angiostatin resulted in significant inhibition in the mean total, endothelial-sprout length. Conversely, all these agents did not seem to interfere with the formation of nonendothelial sprouts. These experiments have been repeated at least three times in over 50 EBs for each experiment and yielded consistent results.

\section{VE-Cadherin Deficiency Results in Defects in Endothelial Cell Sprouting}

One of the major advantages of the ES/EB system is the possibility to investigate in vitro, after the introduc-
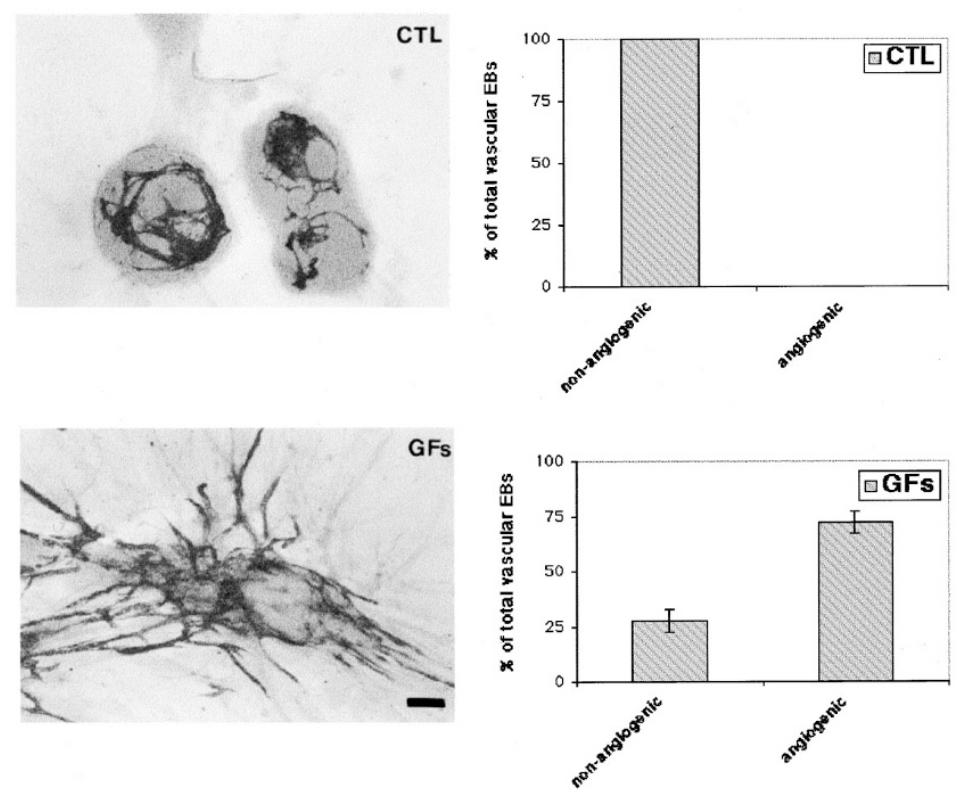

Figure 4.

Endothelial sprouting from 11-day-old EBs embedded into collagen gel is specifically induced by angiogenic growth factors. Eleven-day-old EBs were cultured for 3 days into type I collagen gel in the absence (CTL) or in the presence (GFs) of a mixture of angiogenic factors, before being processed for PECAM whole mount immunostaining to reveal endothelial cells. Nonangiogenic and angiogenic vascular phenotypes were scored among at least 100 vascular EBs in each differentiation experiment. Data are the mean \pm SD of four independent differentiation experiments. Scale bar: $100 \mu \mathrm{m}$. 

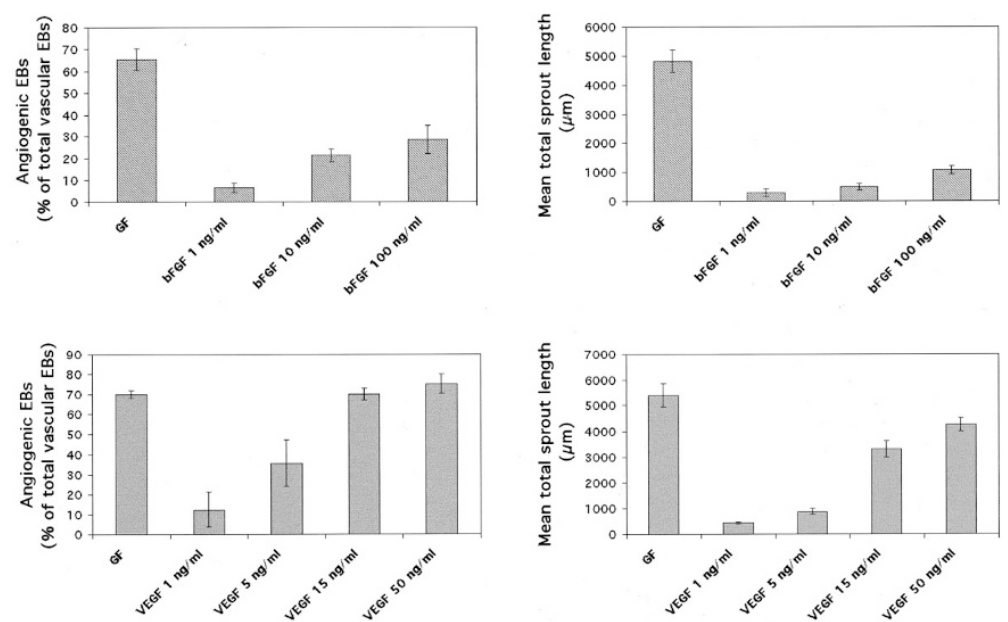

\section{Figure 5.}

Quantitative analysis of angiogenesis activators effects on endothelial sprouting. Effects of basic fibroblast growth factor (FGF2) or vascular endothelial growth factor (VEGF) on proportion of angiogenic EBs and on EB mean total length of endothelial sprouts were measured after 72 hours of collagen secondary culture. Quantitative analysis was performed on at least $30 \mathrm{EBs}$ for each factor concentration. Data represent mean values for 3 independent experiments \pm SE. The left bar indicated as a reference the mean value obtained for the complete GF angiogenic growth factor cocktail at maximal dose.

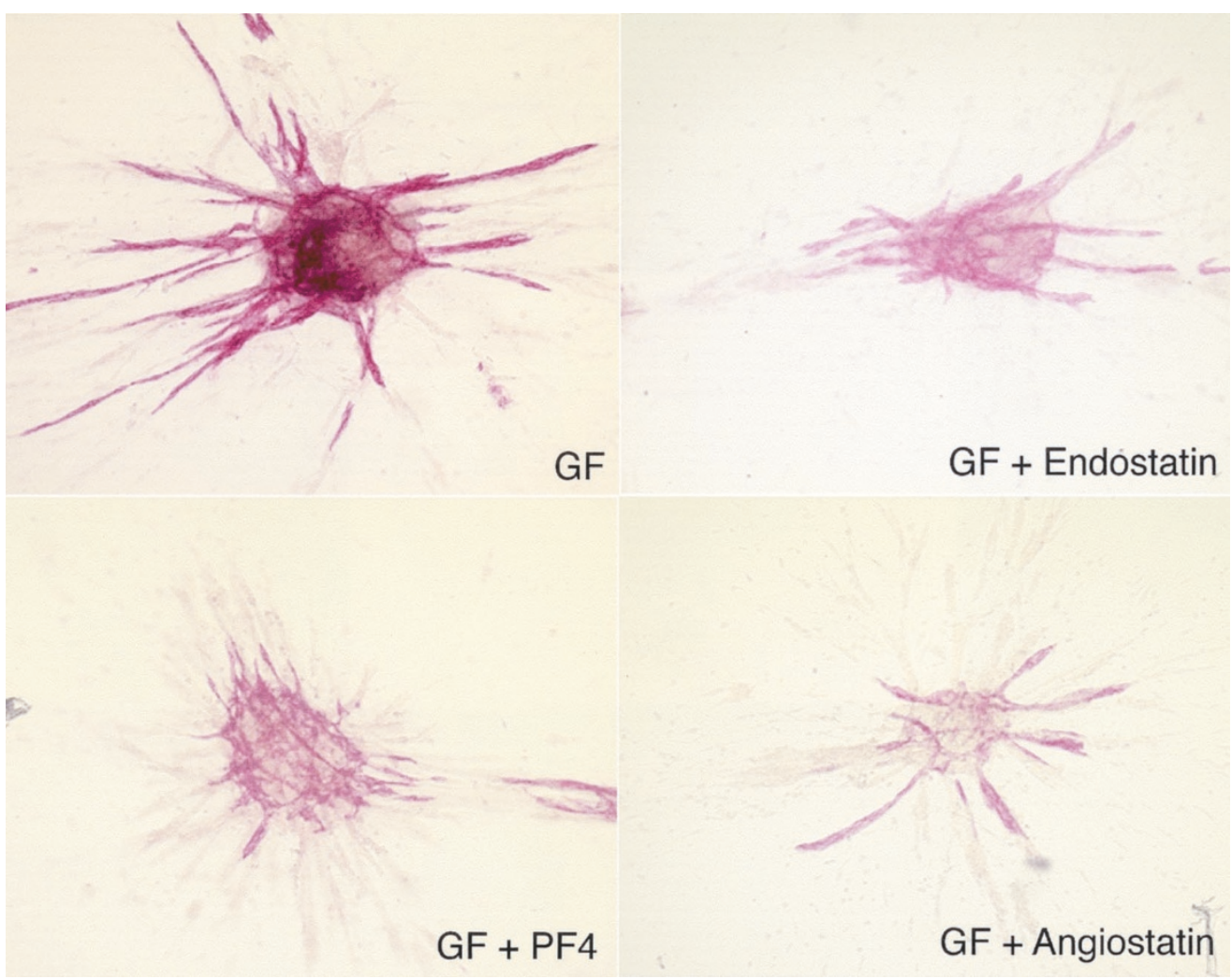

Figure 6.

Effect of angiostatic agents on endothelial sprouting induced by angiogenic GFs. Illustration of endostatin (10 $\mu \mathrm{g} / \mathrm{ml})$, platelet factor 4 (PF4) (5 $\mu \mathrm{g} / \mathrm{ml})$, and angiostatin $(2.5 \mu \mathrm{g} / \mathrm{ml})$ effects on EB endothelial sprouting activity induced by angiogenic GFs.

tion of genetic modifications, the precise contribution of a gene to developmental processes. In addition to early vascular development, VE-cadherin has been shown to play a fundamental role in the angiogenic response, both in vitro and in vivo (Bach et al, 1998; Carmeliet et al, 1999; Gory-Fauré et al, 1999). We then examined the development in collagen gels of VEcadherin deficient EBs originating from the initial dif- ferentiation of two different VE-cadherin -/- ES cell clones (Vittet et al, 1997). In agreement with our previous work (Vittet et al, 1997), we observed defective vascular structures organization in the great majority of VE-cadherin-/-ES-derived EBs after 11 days of differentiation. When placed into collagen gels in the presence of angiogenic factors, the development of cellular outgrowths can still be observed, but VE- 

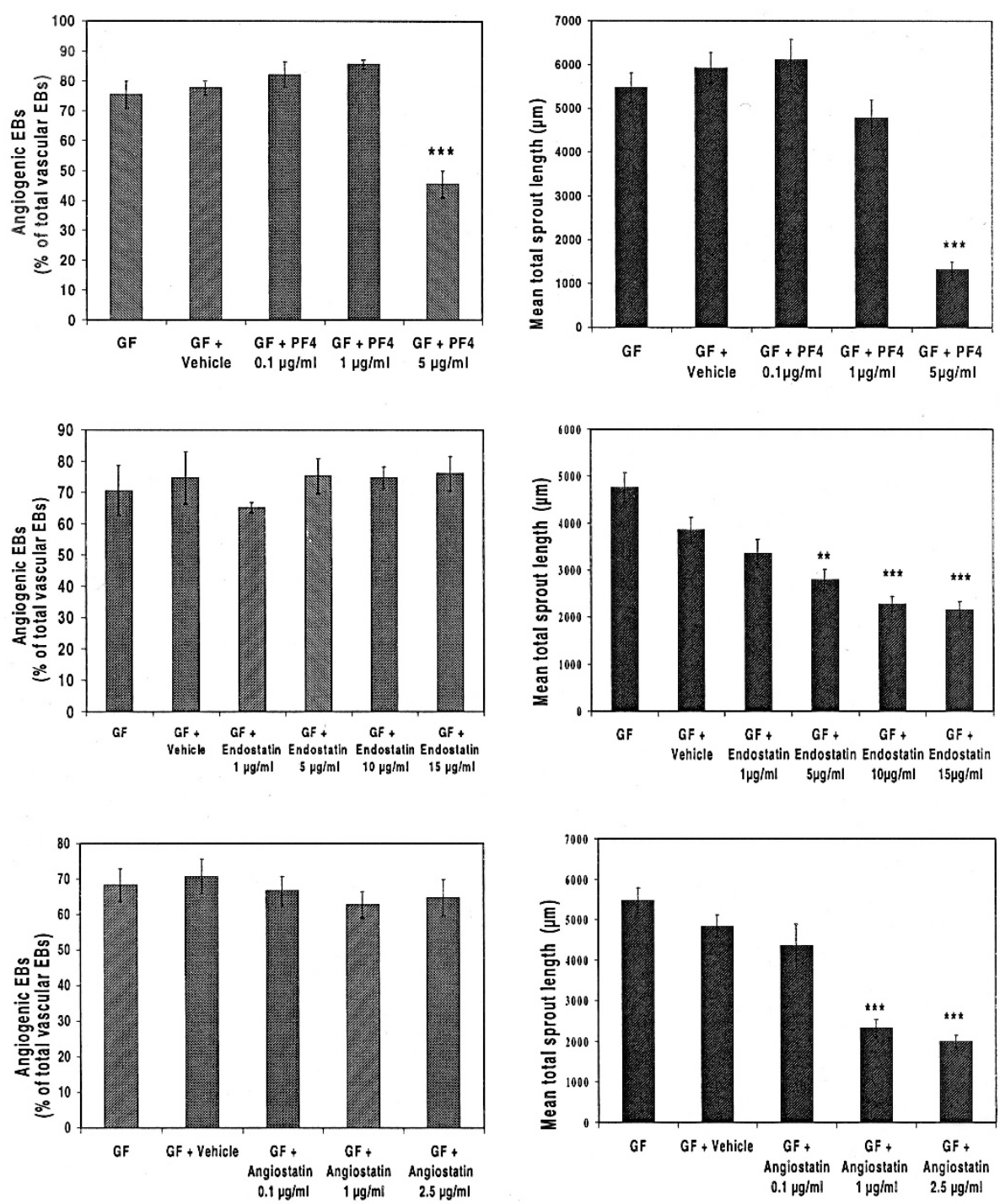

Figure 7.

Quantitative analysis of angiostatic agents effects. EBs were treated with the angiogenic cocktail (GF) in the absence or in the presence of the indicated concentrations of angiogenesis inhibitors or with their corresponding vehicle. Analysis of the percentage of angiogenic EBs and of the mean total sprout length of angiogenic EBs was performed after 3 days of secondary culture into the collagen gel. Data represent mean values for 3 independent experiments $\pm \mathrm{SE}^{* *} p<0.01,{ }^{* \star \star} p<0.001$; significantly different from respective control values corresponding to the addition of the vehicle.

cadherin deficient EBs failed to form a network of branched endothelial sprouts (Fig. 8). On some occasions, some endothelial cells can migrate outside the EBs, but they remained isolated and never organize into capillary-like structures.

\section{Discussion}

The main purpose of the present study was to determine whether ES cells can provide a useful tool to investigate angiogenesis molecular mechanisms. Different types of assay systems have been used to study angiogenesis in vitro, including collagen models, but they at best represent only part of the angiogenic process (Cockerill et al, 1995; Jain et al, 1997). Some previous reports using ES cells have mentioned the formation of an extensive and branched endothelial network from EBs plated onto gelatinized dishes that may probably represent angiogenesis (Bloch et al, 1997; Goumans et al, 1999). Here, we characterized the EB sprouting response obtained into a type I collagen gel. Our data indicate that PECAM-positive vascular sprouts can arise from the EB pre-existing primitive vascular network when they are embedded into a type I collagen gel in the presence of angiogenic factors. The phenotypic characterization of these sprouts confirmed that they represent fully differentiated endothelial cells, because they also expressed VE-cadherin and sometimes vWF, the latter being a heterogenous marker for differential endothelial cell gene expression (Coffin et al, 1991). These endothelial sprouts appeared to further organize into tube-like structures, in parallel with the differentiation of $\alpha$-smooth muscle actin positive cells. Sprouting, progressive elongation, invasion of the interstitium-like 


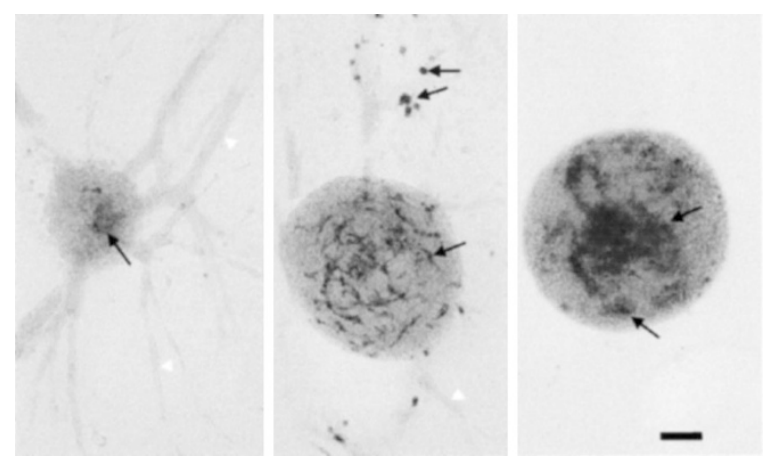

Figure 8.

Embryoid bodies lacking VE-cadherin failed to develop endothelial sprouts into collagen gel. Maturation of 11-day-old EBs resulting from the differentiation of ES cells in which the VE-cadherin gene was inactivated by gene targeting (Vittet et al, 1997) was examined after 3 days of secondary culture in the presence of the angiogenic factor cocktail. Three different VE-cadherin-/- EBs, originating from two different VE-cadherin-/-ES cell clones are illustrated. Whole mount immunostainings with PECAM antibody showed that endothelial cells inside the VE-cadherin-deficient EBs remained dispersed or poorly organized into vascular structures, as previously described (Vittet et al, 1997), and that the formation of a branched network of endothelial outgrowth was impaired. In some occasions, as illustrated by the EB in the center of the figure, some endothelial cells have migrated into the surrounding collagen matrix but the constitution of a sprout was defective. White arrow heads show some nonendothelial outgrowth and examples of PECAM positive cells are shown by black arrows. Scale bar: $100 \mu \mathrm{m}$.

collagen substrate, cell-cell assembly, morphogenesis into tubes, and periendothelial cell differentiation are all features which recapitulate angiogenesis in vivo (Jain et al, 1997; Risau, 1997). In addition, BrDU incorporation assays supported the existence of proliferating endothelial cells, correlating with a complete angiogenic response involving proliferative and migratory responses and morphogenesis.

Moreover, endothelial cells constituting angiogenic EBs were found to display an angiogenic phenotype. Angiogenesis has been characterized to be accompanied by coordinate changes in endothelial cell morphology and gene expression (Auerbach and Auerbach, 1994; Breier et al, 1997). Indeed, during the neovascularization process, endothelial cells change their genetic program and express an angiogenic phenotype by up-regulating several endothelial receptor tyrosine kinases that represent the major signaling system involved in the regulation of the angiogenic response. They include receptors for VEGF (flk-1, flt-1), angiopoietins (tie-2), and the tie-1 receptor (Breier et al, 1997). Activation of flk-1 was reported to be associated with endothelial cell proliferation, whereas the flt-1 receptor seemed to be more involved in the regulation of cell-cell and cell-matrix interactions. Overexpression of flk- 1 has been found in the endothelial cells of angiogenic vessels in several tumor types (Plate et al, 1993). On the other hand, expression of flt-1 was found associated with growing vessels in the wounds (Peters et al, 1993) and its expression level has been shown to be increased in ischemic cardiac tissue, suggesting its involvement in the growth of collateral blood vessels (Li et al, 1996). Essential functions for tie-1 and tie-2 in developmental angiogenic expansion were also revealed by genetic studies in mice (Sato et al, 1993). Both molecules also play a role in normal and pathological angiogenesis in adults (Peters et al, 1998; Wong et al, 1997). Sustained or higher levels of expression for all these tyrosine kinase receptors are observed in angiogenic EBs, thus indicating the induction of an angiogenic phenotype when EBs are cultured in type I collagen gels in the presence of angiogenic factors.

Endothelial sprouting was specifically induced by the angiogenic growth factors exogenously added into the collagen gel. The presence of angiogenic factors was indeed required to undergo the formation of endothelial sprouts into the collagen matrix, because EBs cultured in the absence of these factors failed to develop endothelial sprouts and a marked decrease in angiogenic markers expression was observed. This requirement is consistent with other reports employing similar in vitro models, which mentioned that endothelial cells require angiogenic and/or survival signals to undergo vascular morphogenesis in three dimensional gels (Satake et al, 1998). The decrease in endothelial gene expression observed in the absence of angiogenic factors may be the result of endothelial cell apoptosis, as previously described (Kuzuya et al, 1999; Pollman et al, 1999). Whereas, in the presence of angiogenic factors, endothelial cells may survive, proliferate, and form a capillary-like endothelial network in three dimension. The angiogenic growth factor cocktail used included FGF2, VEGF, erythropoietin (EPO), and interleukin-6 (IL6), which all are known or have been considered to be potent angiogenic inducers (Bikfalvi et al, 1997; Ferrara and Davis-Smyth, 1997; Motro et al, 1990; Ribatti et al, 1999). Among these factors, VEGF has proved to exert a central role in angiogenesis regulation (Neufeld et al, 1999). In our model, a key role is also played by VEGF, because VEGF alone can induce the major part of the sprouting response. Conversely, FGF2, by itself, exhibited only a minor contribution in EB endothelial sprouting, further indicating, as shown by others, that FGF2 does not play a substantial role in angiogenic processes during development (Ortega et al, 1998; Ozaki et al, 1998).

To investigate whether maturation of ES-derived EBs respond to angiostatic agents, and to test the validity of the ES/EB model for the evaluation of molecular mechanisms involved in angiogenesis inhibition, we conducted experiments with angiostatic molecules. A diverse group of angiogenesis inhibitors have been characterized and identified by their ability to inhibit endothelial cell proliferation, migration, cord formation, and to suppress both angiogenesis and tumor growth (Hanahan and Folkman, 1996). These inhibitors include various proteins, such as angiostatin, endostatin, and PF4, which can interfere with new blood vessel formation both in vitro and in vivo (Jouan et al, 1999; Kruger et al, 2000; O’Reilly et al, 1994, 1997; Tanaka et al, 1997). After addition of PF4, endostatin, or angiostatin, the formation of a branched endothelial network was markedly impaired. The active concentrations of these inhibitors were in the $\mu \mathrm{g} / \mathrm{ml}$ range, that is in accordance with what is known from other in vitro studies (Deckers et al, 2001; Kruger 
et al, 2000; Sharpe et al, 1990; Troyanovsky et al, 2001). However, some previous published studies have also reported activity both in vivo and in vitro at much lower endostatin concentrations (Yamaguchi et al, 1999). Endostatin interaction with heparan sulfate was reported to be potentially involved in some of the endostatin effects (Dixelius et al, 2000; Sasaki et al, 1999) and glypican-1 has recently been identified as a low affinity endostatin binding site on endothelial cells (Karumanchi et al, 2001). Our results may then indicate that the observed endostatin inhibitory effect on EB endothelial sprouting may be in part dependent on endostatin binding to heparin/heparan sulfate proteoglycans. Future studies with endostatin heparin binding mutants should bring additional information. On the other hand, higher endostatin activity of recombinant endostatin was reported only when a different in vitro assay (endothelial cell migration) was used (Yamaguchi et al, 1999). The necessity to use higher endostatin concentrations in our assay may be the consequence of the complexity of the response occuring in a multicellular assay, which integrates multiple aspects of the angiogenic response, as observed during outgrowth of capillary structures from fetal mouse bone explants, where endostatin from the same origin as ours exhibited significant inhibitory effects at concentrations not below $1 \mu \mathrm{g} / \mathrm{ml}$ (Deckers et al, 2001). The active concentrations of angiogenesis inhibitors in vitro are not easy to compare with those eliciting angiogenesis inhibition in vivo. Indeed, blood levels of endostatin or angiostatin after protein therapy have not been reported and efficient inhibition of tumor growth is achieved after daily administration of inhibitors, whereas a single addition is performed in our study at the initiation of the secondary culture in the collagen gel. Nonetheless, the active concentrations of angiostatic factors on EB endothelial sprouting are consistent with circulating levels eliciting significant angiogenesis inhibition resulting in inhibition of tumor growth, which are obtained after gene transfer (Kuo et al, 2001; Sauter et al, 2000). Then, the ability of these well-known angiogenesis inhibitors to significantly inhibit the EB angiogenic sprouting response indicated that this model could be of primary importance in investigating the angiostatic molecules' mechanisms of action that remain largely unknown (Risau, 1997). Furthermore, this model will enable us to characterize which parameters of the angiogenic response (proliferation, sprouting, branching, etc.) are targets for these angiostatic molecules. In addition, virtually nothing is known about the effects of angiostatic molecules on angioblasts differentiation. This model will also offer the opportunity to investigate this aspect.

To evaluate the potency of the ES/EB model to investigate angiogenesis molecular mechanisms, we looked at the maturation of VE-cadherin -/- ESderived EBs and compared it with the published in vivo phenotype. Deficiency in the junctional interendothelial VE-cadherin adhesion protein has been previously reported to impair sprouting and remodeling into a network of large and small branches (Carmeliet et al, 1999). We also clearly found in our model that endothelial sprouting failed to take place in the absence of VE-cadherin. This model may then be particularly useful for the analysis of the consequences of specific gene modification.

Although in vivo models such as the corneal neovascularization model, the mesenteric window assay, and numerous pouch assays display a more complete portrait of angiogenesis, inflammation caused by wounding and matrix implantation makes angiogenesis sometimes difficult to assess (Jain et al, 1997). The ES/EB model system has the advantage to be devoid of interference with host responses. Moreover, it may constitute an alternative to animal experimentation, which suffers from ethical constraints. Moreover, the ES/EB system allows the study of both vasculogenesis and angiogenesis, which is a unique property conferring superiority to all other in vitro angiogenesis models. In addition, the differentiation of genetically modified ES cells by gain-of-function and loss-of-function analyses are also excellent alternatives and substitutes to in vivo studies with transgenic animals to analyze the consequences of mutations on vascular development. Finally, this model responding to both positive and negative modulators of angiogenesis can be exploited for the identification of novel signaling molecules. Because the number of new antiangiogenic agents is rapidly increasing, each of them representing promising tools in therapy, but whose molecular mechanisms of action remained largely unsolved, this model may be particularly useful to identify their cellular targets as well as differentially expressed genes during new blood vessel formation.

\section{Materials and Methods}

\section{ES Cell Differentiation}

Subconfluent CJ7-ES cells (Swiatek and Gridley, 1993) or R1-ES cells (Naguy et al, 1993) were initiated to differentiate in Iscove's medium containing glutamax (IMDM; Invitrogen, Carlsbad, California) supplemented with $1 \%$ methylcellulose (Stem Cell Technologies Inc., Vancouver, Canada), 15\% fetal calf serum (Seromed, Berlin, Germany), $450 \mu \mathrm{M}$ monothioglycerol, $10 \mu \mathrm{g} / \mathrm{ml}$ insulin (Roche Diagnostics, Meylan, France), $50 \mathrm{U} / \mathrm{ml}$ penicillin, and $50 \mu \mathrm{g} / \mathrm{ml}$ streptomycin. To optimize endothelial differentiation, ES cell differentiation was performed in the presence of 50 $\mathrm{ng} / \mathrm{ml}$ human VEGF (Peprotech, Rocky Hill, New Jersey), $100 \mathrm{ng} / \mathrm{ml}$ human FGF2 (Peprotech), $2 \mathrm{U} / \mathrm{ml}$ mouse EPO (Roche Diagnostics) and $10 \mathrm{ng} / \mathrm{ml}$ murine IL6 (Peprotech), as described previously (Vittet et al, 1996). ES cells $\left(1.25 \times 10^{3}\right.$ cells $\left./ \mathrm{ml}\right)$ were seeded in a final volume of $2 \mathrm{ml}$ in $35-\mathrm{mm}$ bacterial grade Petri dishes (Greiner, Nurtingen, Germany).

\section{EB Maturation into Type I Collagen Gels}

For secondary culture into collagen gel, EBs were collected after 11 days of differentiation by dilution of the semi-solid methylcellulose medium with IMDM 
Glutamax. After centrifugation (200×g, 5 minutes) and two further washes, EBs were suspended in IMDM Glutamax and mixed with the collagen culture medium at a final concentration of $50 \mathrm{EBs} / \mathrm{ml}$. Final composition of freshly prepared collagen-based culture medium was as follows: IMDM containing $1.25 \mathrm{mg} / \mathrm{ml}$ rat tail collagen, type I (lot 900649; Becton Dickinson, Bedford, Massachusetts), 15\% fetal calf serum (Seromed), $450 \mu \mathrm{M}$ monothioglycerol, $10 \mu \mathrm{g} / \mathrm{ml}$ insulin, 50 $\mathrm{U} / \mathrm{ml}$ penicillin, and $50 \mu \mathrm{g} / \mathrm{ml}$ streptomycin. After thorough mixing of EBs into collagen-based medium, 1.2 $\mathrm{ml}$ were dispensed into $35-\mathrm{mm}$ bacterial Petri dishes. When tested, factors were included into the collagen gel medium at the onset of the culture. Neutralization of the acidity of the collagen solution by the medium, in combination with incubation at $37^{\circ} \mathrm{C}$, promotes within 30 minutes the formation of a stable collagen gel matrix. Cultures are then incubated up to 3 days in the presence or in the absence of angiogenic and/or angiostatic agents before harvest and analysis of their vascular development.

\section{Angiogenesis Inhibitors}

The Kringle 1-4 (K1-4) angiostatin was prepared by digestion of Glu-human plasminogen (Glu-HPg) with porcine elastase as previously described (Cao et al, 1996). Briefly, $3 \mathrm{mg}$ elastase was incubated at room temperature with $400 \mathrm{mg}$ of $\mathrm{HPg}$ in $50 \mathrm{~mm}$ Tris- $\mathrm{HCl}$, $\mathrm{pH} 8.0$ overnight with shaking. The reaction was terminated by the addition of diisopropyl fluorophosphate (DFP) to a final concentration of $1 \mathrm{~mm}$. The mixture was rocked for an additional 30 minutes at room temperature and dialyzed overnight against 50 $\mathrm{mm}$ Tris- $\mathrm{HCl}, \mathrm{pH}$ 8.0. The proteolytically cleaved $\mathrm{K} 1-4$ angiostatin was purified using a lysine-Sepharose 4B column $(2.5 \times 15 \mathrm{~cm})$ (Amersham Pharmacia Biotech,
Orsay, France) equilibrated with $50 \mathrm{~mm}$ Tris- $\mathrm{HCl}, \mathrm{pH}$ 8.0. Angiostatin was eluted with the Tris buffer containing 200-mm $\Sigma$-aminocaproic acid, $\mathrm{pH}$ 8.0. The eluted samples were then dialyzed overnight against $20 \mathrm{~mm}$ Tris- $\mathrm{HCl}, \mathrm{pH} 5.0$ and were applied to a BioRad Mono-S column equilibrated with the same buffer. After dialysis, K1-4 angiostatin (Biorad Laboratories, Hercules, California) was separated from K1-3 using a heparin-Sepharose column $(5 \mathrm{~cm} \times 10 \mathrm{~cm}$ ) (Sigma Instruments, Monterey, California) pre-equilibrated with $20 \mathrm{~mm}$ Tris- $\mathrm{HCl}$ buffer, $\mathrm{pH}$ 8.0. The $\mathrm{K} 1-3$ fragment was eluted with $250 \mathrm{~mm} \mathrm{KCl}$ and $\mathrm{K} 1-4$ was recovered from the flow-through fraction. The purified kringle fragments were analyzed on SDS-gels followed by staining with Coomassie blue.

Either recombinant (Peprotech) and purified (Diagnostica Stago, Asnières, France) human PF4 were used. Purified soluble recombinant human endostatin derived from the EBNA 293 embryonic kidney cell line (Yamaguchi et al, 1999) was provided by Dr. Bjorn Olsen (Harvard Medical School, Boston, Massachusetts).

\section{Immunofluorescence Analysis, Whole Mount Immunocytochemistry and BrdU Labeling}

Collagen gels containing EBs were collected onto glass slides, then dehydrated in seconds using a nylon linen and absorbent filter cards. Indirect immunofluorescence experiments were performed as described (Vittet et al, 1996, 1997) with: rat monoclonal antimouse PECAM antibody (clone MEC-13.3) (Vecchi et al, 1994), rat monoclonal anti-mouse Flk-1 antibody (clone AVAS12; provided by Dr. S-I. Nishikawa, Department of Molecular Genetics, Kyoto University, Kyoto, Japan) (Nishikawa et al, 1998), rabbit polyclonal anti-human vWF (Dako S.A., Trappes, France), and rat monoclonal anti-mouse VE-cadherin antibody (clone 11D4.1; Pharmingen, San Diego, California).
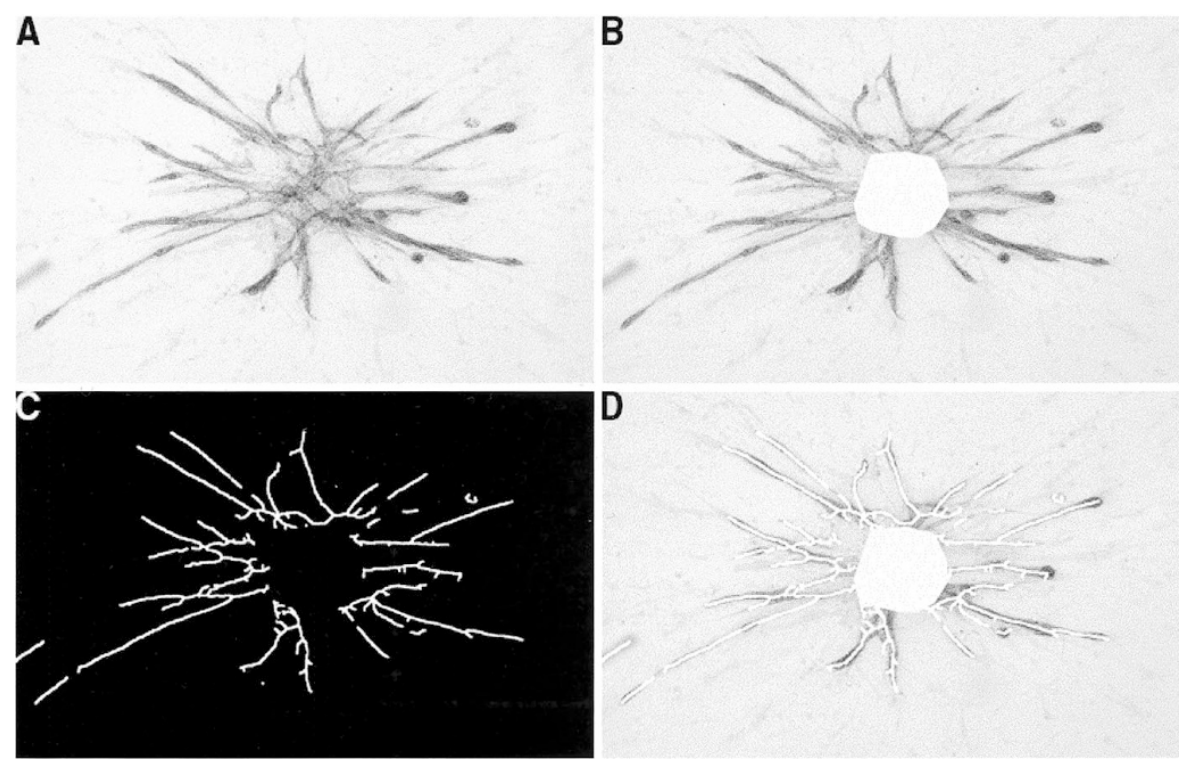

Figure 9.

Image processing for quantification of endothelial sprouting. A, Image of PECAM staining captured by CCD camera. B, Image A from which the area corresponding to the body mass is subtracted. C, Skeletonized image of the PECAM staining of image B. D, Superposition of image $C$ and image A. 
For whole-mount PECAM staining, EBs embedded into collagen gels were fixed in methanoldimethylsulfoxide (4:1) overnight at $4^{\circ} \mathrm{C}$ and stained with rat monoclonal anti-mouse PECAM antibody (clone MEC-13.3) as previously described (Vittet et al, 1997). Dehydrated collagen gels, prepared as outlined above, were then mounted in aqueous medium onto glass slides before microscope examination.

For the detection of proliferating cells, the gels were covered, at Day 2 of EB secondary culture, with $1 \mathrm{ml}$ IMDM-based medium containing $50 \mu \mathrm{M}$ BrdU (Sigma, St. Quentin Fallavier, France) for 6 hours. After 4 washes with PBS, collagen gels were turned out onto glass slides and dehydrated. Fixation was done with 4\% paraformaldehyde for 20 minutes at room temperature. Dividing endothelial cells were then revealed by double immunofluorescence using monoclonal antimouse PECAM antibody (MEC-13.3) and monoclonal anti-BrdU antibody (Sigma), as described (Deloulme et al, 1991).

\section{Reverse Transcription-Polymerase Chain Reaction (RT-PCR)}

EBs were collected after digestion of the collagen matrix by 30 minutes treatment at $37^{\circ} \mathrm{C}$ with a PBS solution containing $0.2 \%$ collagenase B (Roche Diagnostics). Semiquantitative RT-PCR was performed as previously described (Vittet et al, 1996). After prior treatment with RQ1 DNase to eliminate any contaminating genomic DNA, $2 \mu \mathrm{g}$ of total RNA was reversetranscribed. The equivalent of $200 \mathrm{ng}$ reversetranscribed RNA was used for PCR experiments. All PCR analyses were performed using exponential amplification conditions. Annealing temperature and PCR cycle numbers were: $55^{\circ} \mathrm{C}, 27$ cycles; $55^{\circ} \mathrm{C}, 30$ cycles; $60^{\circ} \mathrm{C}, 32$ cycles; $55^{\circ} \mathrm{C}, 30$ cycles, and $57^{\circ} \mathrm{C}$, 32 cycles for flk-1, hprt, flt-1, tie-1, and tie-2, respectively. Reaction products were gel electrophoresed, transferred onto nylon membrane (Hybond $\mathrm{N}+$; Amersham Pharmacia Biotech, Les Ullis, France), and hybridized with their respective $\left[{ }^{32} \mathrm{P}\right]-5$ '-end-labeled internal oligonucleotide probe according to standard protocols (Sambrook et al, 1989). Hybridized filters were visualized and signals quantified using a Phosphorlmager (Molecular Dynamics, Sunnyvale, California).

Oligonucleotide primers and probes to analyze flk-1, tie-2 and hprt gene expression were described in Vittet et al, 1996. For flt-1 gene expression, the primers were those described by Choi et al, 1998, and the probe was: 5'-AGAAGCCCCGCCTAGACA-3'. For tie-1 gene expression, the primers were as follows 5'-TCTCTATGTGCACAACAGCC-3' (sense), 5'-ACACACACATTCGCCATCAT-3' (antisense), and the probe was 5'-TGACGGGCGTTTTCAACTGC-3' .

\section{Computer-Assisted Morphometric Analysis of Vascular Sprouting}

For quantitation of endothelial sprouting from the EBs, EBs embedded into collagen gels were immunostained with anti-PECAM antibodies by the whole mount procedure. Images were captured with a Spot computersupported digital camera. After masking the EB area, the resulting image comprising endothelial sprouts alone was binarized to black/white and skeletonized (Fig. 9). Measurement of the total length of endothelial sprouts was achieved by using the visiolab@2000 software (BIOCOM, Les Ulis, France). The results were subjected to statistical analysis by the paired Student's $t$ test; the level of significance was set as $p<0.05$.

\section{Acknowledgements}

The authors thank Dr. Dietmar Westveber for providing CJ7 ES cell line, Dr. Andras Naguy for R1 ES cell line, Dr. Shin-Ichi Nishikawa for antibodies, and Dr. Bjorn Ölsen for recombinant human endostatin. The authors are also indebted to Mrs. Annie Schweitzer and Dr. Marie-Hélène Prandini for discussion, advice, and skillful assistance. We also thank Drs. Thierry Buchou and Philippe Huber for critical reading of the manuscript.

\section{References}

Asahara T, Murohara T, Sullivan A, Silver M, Van der Zee R, Li T, Witzenbichler B, Schatteman G, and Isner JM (1997). Isolation of putative progenitor endothelial cells for angiogenesis. Science 275:964-967.

Asahara T, Takahashi T, Masuda H, Kalka C, Ghen D, Iwaguro H, Inai $\mathrm{Y}$, Silver M, and Isner JM (1999). VEGF contributes to postnatal neovascularization by mobilizing bone marrow-derived endothelial progenitor cells. EMBO J 18:3964-3972.

Auerbach W and Auerbach R (1994). Angiogenesis inhibition: A review. Pharmacol Ther 63:265-311.

Bach TL, Barsigian C, Chalipowicz DG, Busler D, Yaen CH, Grant DS, and Martinez J (1998). VE-cadherin mediates endothelial cell capillary tube formation in fibrin and collagen gels. Exp Cell Res 238:324-334.

Beck L and D'Amore PA (1997). Vascular development: Cellular and molecular regulation. FASEB J 11:365-373.

Bikfalvi A, Klein S, Pintucci G, and Rifkin DB (1997). Biological roles of fibroblast growth factor-2. Endocrine Rev 18:26-45.

Bloch W, Forsberg E, Lentini S, Brakebusch C, Martin K, Krell HW, Weidle UH, Addicks K, and Fässler R (1997). $\beta 1$ integrin is essential for teratoma growth and angiogenesis. J Cell Biol 139:265-278.

Breier G, Damert A, Plate KH, and Risau W (1997). Angiogenesis in embryos and ischemic diseases. Thromb Haemost 78:678683.

Cao Y, Ji RW, Davidson D, Schaller J, Marti D, Sohndel S, McGance SG, O'Reilly MS, Llinas M, and Folkman J (1996). Kringle domains of human angiostatin. Characterization of the anti-proliferative activity on endothelial cells. J Biol Chem 271: 29461-29467.

Carmeliet P and Collen D (2000). Transgenic mouse models in angiogenesis and cardiovascular disease. J Pathol 190:387-405.

Carmeliet P, Lampugnani MG, Moons L, Breviaro F, Compernolle V, Bono F, Balconi G, Spagnuolo R, Oosthuyse B, Dewerchin M, Zanetti A, Angellilo A, Mattot V, Nuyens D, Lutgens E, Clotman F, De Ruiter MC, Gittenberger-de Groot A, Poelmann R, Lupu F, Herbert JM, Collen D, and Dejana E (1999). Targeted deficiency or cytosolic truncation of the VE-cadherin gene in mice impairs VEGF-mediated endothelial survival and angiogenesis. Cell 98: $147-157$. 
Choi K, Kennedy M, Kazarov M, Papadimitriou JC, and Keller G (1998). A common precursor for hematopoietic and endothelial cells. Development 125:725-732.

Cockerill GW, Gamble JR, and Vadas MA (1995). Angiogenesis: Models and modulators. Int Rev Cytol 159:113-160.

Coffin JD, Harrison J, Schwartz S, and Heimark R (1991). Angioblast differentiation and morphogenesis of the vascular endothelium in the mouse embryo. Dev Biol 148:51-62.

Deckers M, Van der Pluijm G, Dooijewaard S, Kroon M, Van Hinsbergh V, Papapoulos S, and Löwik C (2001). Effect of angiogenic and antiangiogenic compounds on the outgrowth of capillary structures from fetal mouse bone explants. Lab Invest 81:5-15

Deloulme J-C, Baudier J, and Sensenbrenner M (1991). Establishment of pure neuronal cultures from fetal rat spinal cord and proliferation of the neuronal precursor cells in the presence of fibroblast growth factor. J Neurosci Res 29:499-509.

Dixelius J, Larsson H, Sasaki T, Holmqvist K, Lu L, Engström A, Timpl R, Welsh M, and Claesson-Welsh L (2000). Endostatininduced tyrosine kinase signaling through the Shb adapter protein regulates endothelial cell apoptosis. Blood 95:3403-3411.

Ferrara N and Davis-Smyth T (1997). The biology of vascular endothelial growth factor. Endocr Rev 18:4-25.

Flamme I, Frölich T, and Risau W (1997). Molecular mechanisms of vasculogenesis and embryonic angiogenesis. J Cell Physiol 173:206-210.

Gale NW and Yancopoulos GD (1999). Growth factors acting via endothelial cell-specific receptor tyrosine kinases: VEGFs, angiopoietins, and ephrins in vascular development. Genes Dev 13: 1055-1066.

Garlanda C, Parravicini C, Sironi M, De Rossi M, Wainstok de Calmanovici R, Carozzi F, Bussolino F, Colotta F, Mantovani A, and Vecchi A (1994). Progressive growth in immunodeficient mice and host cell recruitment by mouse endothelial cells transformed by polyoma middle-sized T antigen: Implications for the pathogenesis of opportunistic vascular tumors. Proc Natl Acad Sci USA 91:7291-7295.

Gerber H-P, McMurtrey A, Kowalski J, Yan M, Keyt BA, Dixit V, and Ferrara N (1998). Vascular endothelial growth factor regulates endothelial cell survival through the phosphatidylinositol 3'-kinase/Akt signal transduction pathway. J Biol Chem 273: 30336-30343.

Gory-Fauré S, Prandini $\mathrm{M}-\mathrm{H}$, Pointu $\mathrm{H}$, Roullot $\mathrm{V}$, PignotPaintrand I, Vernet M, and Huber P (1999). Role of vascularendothelial cadherin in vascular morphogenesis. Development 126:2093-2102.

Goumans M-J, Zwijsen A, Van Rooijen MAV, Huylebroeck D, Roelen BAJ, and Mummery CL (1999). Transforming growth factor-b signaling in extraembryonic mesoderm is required for yolk sac vasculogenesis in mice. Development 126:3473-3483.

Hanahan D and Folkman J (1996). Patterns and emerging mechanisms of the angiogenic switch during tumorigenesis. Cell 86:353-364.

Hirashima M, Kataoka H, Nishikawa S, Matsuyoshi N, and Nishikawa S-I (1999). Maturation of embryonic stem cells into endothelial cells in an in vitro model of vasculogenesis. Blood 93:1253-1263.

Jain RK, Schlenger K, Höckel M, and Yuan F (1997). Quantitative angiogenesis assays: Progress and problems. Nature Med 3:1203-1208.

Jouan V, Canron X, Alemany M, Caen JP, Quentin G, Plouet J, and Bikfalvi A (1999). Inhibition of in vitro angiogenesis by platelet factor-4-derived peptides and mechanism of action. Blood 94: 984-993.

Kalka C, Masuda H, Takahashi T, Kalka-Moll WM, Silver M, Kearney M, Li T, Isner JM, and Asahara T (2000). Transplantation of ex vivo expanded endothelial progenitor cells for therapeutic neovascularization. Proc Natl Acad Sci USA 97:3422-3427.

Karumanchi SA, Jha V, Ramchandran R, Karihaloo A, Tsiokas L, Chan B, Dhanabal M, Hanai JI, Venkataraman G, Shiver Z, Keiser $\mathrm{N}$, Kalluri R, Zeng $\mathrm{H}$, Mukhopadhyay $\mathrm{D}$, Chen RL, Lander $A D$, Hagihara K, Yamaguchi Y, Sasisekharan R, Cantley L, and Sukhatme VP (2001). Cell surface glypicans are low-affinity endostatin receptors. Mol Cell 7:811-822.

Kruger EA, Duray PH, Tsokos MG, Venzon DJ, Libutti SK, Dixon SC, Rudek MA, Pluda J, Allegra C, and Figg WD (2000). Endostatin inhibits microvessel formation in the ex vivo rat aortic ring angiogenesis assay. Biochem Biophys Res Commun 268:183191.

Kuo CJ, Farnebo F, Yu EY, Christofferson R, Swearingen RA, Carter R, von Recum HA, Yuan J, Kamihara J, Flynn E, D'Amato R, Folkman J, and Mulligan RC (2001). Comparative evaluation of the antitumor activity of antiangiogenic proteins delivered by gene transfer. Proc Natl Acad Sci USA 98:4605-4610.

Kuzuya M, Satake S, Ramos MA, Kanda S, and Iguchi A (1999). Induction of apoptotic cell death in vascular endothelial cells cultured in three-dimensional collagen lattice. Exp Cell Res 248:498-508.

Li J, Brown LF, Hibberd MG, Grossman JD, Morgan JP, and Simons M (1996). VEGF, flk-1, and flt-1 expression in a rat myocardial infarction model of angiogenesis. Am J Physiol 270: H1803-H1811.

Montesano R, Soriano JV, Pepper MS, and Orci L (1997). Induction of epithelial branching tubulogenesis in vitro. J Cell Physiol 173:152-161.

Motro B, Itin A, Sachs L, and Keshet E (1990). Pattern of interleukin 6 gene expression in vivo suggests a role for this cytokine in angiogenesis. Proc Natl Acad Sci USA 87:3092-3096.

Naguy A, Rossant J, Nagy R, Abramow-Newerly W, and Roder JC (1993). Derivation of completely cell culture-derived mice from early-passage embryonic stem cells. Proc Natl Acad Sci USA 90:8424-8428.

Neufeld G, Cohen T, Gengrinovitch S, and Poltorak Z (1999). Vascular endothelial growth factor (VEGF) and its receptors. FASEB J 13:9-22.

Nishikawa S-I, Nishikawa S, Hirashima M, Matsuyoshi N, and Kodama H (1998). Progressive lineage analysis by cell sorting and culture identifies FLK1 + VE-cadherin + cells at a diverging point of endothelial and hemopoietic lineages. Development 125:1747-1757.

O'Reilly MS, Boehm T, Shing Y, Fukai N, Vasios G, Lane WS, Flynn E, Birkhead JR, Olsen BR, and Folkman J (1997). Endostatin: An endogenous inhibitor of angiogenesis and tumor growth. Cell 88:277-285.

O'Reilly MS, Holmgren L, Shing Y, Chen C, Rosenthal RA, Moses M, Lane WS, Cao Y, Sage EH, and Folkman J (1994). Angiostatin: A novel angiogenesis inhibitor that mediates the suppression of metastases by a Lewis lung carcinoma. Cell 79:315-328.

Ortega S, Ittmann M, Tsang SH, Ehrlich M, and Basilico C (1998). Neuronal defects and delayed wound healing in mice lacking fibroblast growth factor 2. Proc Natl Acad Sci USA 95:56725677.

Ozaki H, Okamoto N, Ortega S, Chang M, Ozaki K, Sadda S, Vinores MA, Derevjanik N, Zack DJ, Basilico C, and Campochiaro PA (1998). Basic fibroblast growth factor is neither necessary nor sufficient for the development of retinal neovascularization. Am J Pathol 153:757-765.

Peters KG, Coogan A, Berry D, Marks J, Iglehart JD, Kontos CD, Rao P, Sankar S, and Trogan E (1998). Expression of Tie-2/Tek in breast tumour vasculature provides a new marker for evaluation of tumour angiogenesis. Brit J Cancer 77:51-56. 
Peters KG, De Vries C, and Williams LT (1993). Vascular endothelial growth factor receptor expression during embryogenesis and tissue repair suggests a role in endothelial differentiation and blood vessel growth. Proc Natl Acad Sci USA 90:8915-8919.

Plate KH, Breier G, Millauer B, Ullrich A, and Risau W (1993). Up-regulation of vascular endothelial growth factor and its cognate receptors in a rat glioma model of tumor angiogenesis. Cancer Res 53:5822-5827.

Pollman MJ, Naumovski L, and Gibbons GH (1999). Endothelial cell apoptosis in capillary network remodeling. J Cell Physiol 178:359-370.

Rathjen PD, Lake J, Whyatt LM, Bettess MD, and Rathjen J (1998). Properties and uses of embryonic stem cells: Prospects for application to human biology and gene therapy. Reprod Fertil Dev 10:31-47.

Ribatti D, Presta M, Vacca A, Ria R, Giuliani R, Dell'Era P, Nico B, Roncali L, and Dammacco F (1999). Human erythropoietin induces a pro-angiogenic phenotype in cultured endothelial cells and stimulates neovascularization in vivo. Blood 93:2627-2636.

Risau, W (1997). Mechanisms of angiogenesis. Nature 386:671674.

Risau W, Sariola H, Zerwes H-G, Sasse J, Ekblom P, Kemler R, and Doetschman $T$ (1988). Vasculogenesis and angiogenesis in embryonic-stem-cell-derived embryoid bodies. Development 102:471-478.

Sambrook J, Fritsch EF, and Maniatis T (1989). Molecular cloning: A laboratory manual, 2nd ed. Cold Spring Harbor, NY: Cold Spring Harbor Laboratory.

Sasaki T, Larsson H, Kreuger J, Salmivirta M, Claesson-Welsh L, Lindahl U, Hohenester E, and Timpl R (1999). Structural basis and potential role of heparin/heparan sulfate binding to the angiogenesis inhibitor endostatin. EMBO J 18:6240-6248.

Satake S, Kuzuya M, Ramos MA, Kanda S, and Iguchi A (1998). Angiogenic stimuli are essential for survival of vascular endothelial cells in three-dimensional collagen lattice. Biochem Biophys Res Commun 244:642-646.

Sato TN, Qin Y, Kozak CA, and Audus KL (1993). Tie-1 and tie-2 define another class of putative receptor tyrosine kinase genes expressed in early embryonic vascular system. Proc Natl Acad Sci USA 90:9355-9358.

Sauter BV, Martinet O, Zhang W-J, Mandeli J, and Woo SLV (2000). Adenovirus-mediated gene transfer of endostatin in vivo results in high level of transgene expression and inhibition of tumor growth and metastases. Proc Natl Acad Sci USA 97:48024807.

Sharpe RJ, Byers HR, Scott CF, Bauer SI, and Maione TE (1990). Growth inhibition of murine melanoma and human colon carcinoma by recombinant human platelet factor 4 . J Natl Cancer Inst 82:848-853.

Sims DE (2000). Diversity within pericytes. Clin Exp Pharmacol Physiol 27:842-846.

Strömbald S and Cheresh DA (1996). Cell adhesion and angiogenesis. Trends Cell Biol 6:462-467.
Swiatek PJ and Gridley T (1993). Perinatal lethality and defects in hindbrain development in mice homozygous for a targeted mutation of the zinc finger gene Krox20. Genes Dev 7:2071-2084.

Tanaka T, Manome Y, Wen P, Kufe DW, and Fine HA (1997). Viral vector-mediated transduction of a modified platelet factor 4 cDNA inhibits angiogenesis and tumor growth. Nature Med 3:437-442.

Troyanovsky B, Levchenko T, Mansson G, Matvijenko O, and Holmgren $L$ (2001). Angiomotin: An angiostatin binding protein that regulates endothelial cell migration and tube formation. $\mathrm{J}$ Cell Biol 152:1247-1254.

Uyttendaele H, Soriano JV, Montesano R, and Kitajewski J (1998). Notch4 and Wnt-1 proteins function to regulate branching morphogenesis of mammary epithelial cells in an opposing fashion. Dev Biol 196:204-217.

Vecchi A, Garlanda C, Lampugnani MG, Resnati M, Matteuci C, Stoppaciaro A, Schnurch H, Risau W, Mantovani A, and Dejana E (1994). Monoclonal antibodies specific for endothelial cells of mouse blood vessels. Their application in the identification of adult and embryonic endothelium. Eur J Cell Biol 63:247-254.

Vittet D, Buchou T, Schweitzer A, Dejana E, and Huber P (1997). Targeted null-mutation in the vascular endothelial-cadherin gene impairs the organization of vascular-like structures in embryoid bodies. Proc Natl Acad Sci USA 94:6273-6278.

Vittet D, Prandini M-H, Berthier R, Schweitzer A, Martin-Sisteron H, Uzan G, and Dejana E (1996). Embryonic stem cells differentiate in vitro to endothelial cells through successive maturation steps. Blood 88:3424-3431.

Wang R, Clark R, and Bautch VL (1992). Embryonic stem cell-derived cystic embryoid bodies form vascular channels: An in vitro model of blood vessel development. Development 114: 303-316.

Wartenberg M, Günther J, Hescheler J, and Sauer H (1998). The embryoid body as a novel in vitro assay system for antiangiogenic agents. Lab Invest 78:1301-1314.

Wong AL, Haroon ZA, Dewhirst MW, Greenberg CS, and Peters KG (1997). Tie-2 expression and phosphorylation in angiogenic and quiescent adult tissues. Circ Res 81:567-574.

Yamaguchi N, Anand-Apte B, Lee M, Sasaki T, Fukai N, Shapiro R, Que I, Lowik C, Timpl R, and Olsen BR (1999). Endostatin inhibits VEGF-induced endothelial cell migration and tumor growth independently of zinc binding. EMBO J 18:4414-4423.

Yamashita J, Itoh H, Hirashima M, Ogawa M, Nishikawa S, Yurugi T, Naito M, Nakao K, and Nishikawa S-I (2000). Flk1-positive cells derived from embryonic stem cells serve as vascular progenitors. Nature 408:92-96.

Yang S, Graham J, Kahn JW, Schwartz EA, and Gerritsen ME (1999). Functional roles for PECAM-1 (CD31) and VE-cadherin (CD144) in tube assembly and lumen formation in threedimensional collagen gels. Am J Pathol 155:887-895. 